\title{
Hydrothermal Reactions of Biomass-derived Platform Molecules: Distinct Effect of Aprotic and Protic Solvents on Primary Decomposition of Glucose and Fructose in Hot- Compressed Solvent/Water Mixtures
}

Bing Song, Zhiliang Wu, Yun $\mathrm{Yu}^{*}$, Hongwei $\mathrm{Wu}^{*}$

Discipline of Chemical Engineering, Western Australian School of Mines: Minerals, Energy and Chemical Engineering, Curtin University, GPO Box U1987, Perth WA 6845, Australia

* Corresponding Authors.

Fax: +61-8-92662681 (Y. Yu and H. Wu)

E-mail addresses: yun.yu@curtin.edu.au (Y. Yu), h.wu@ curtin.edu.au (H.Wu). 


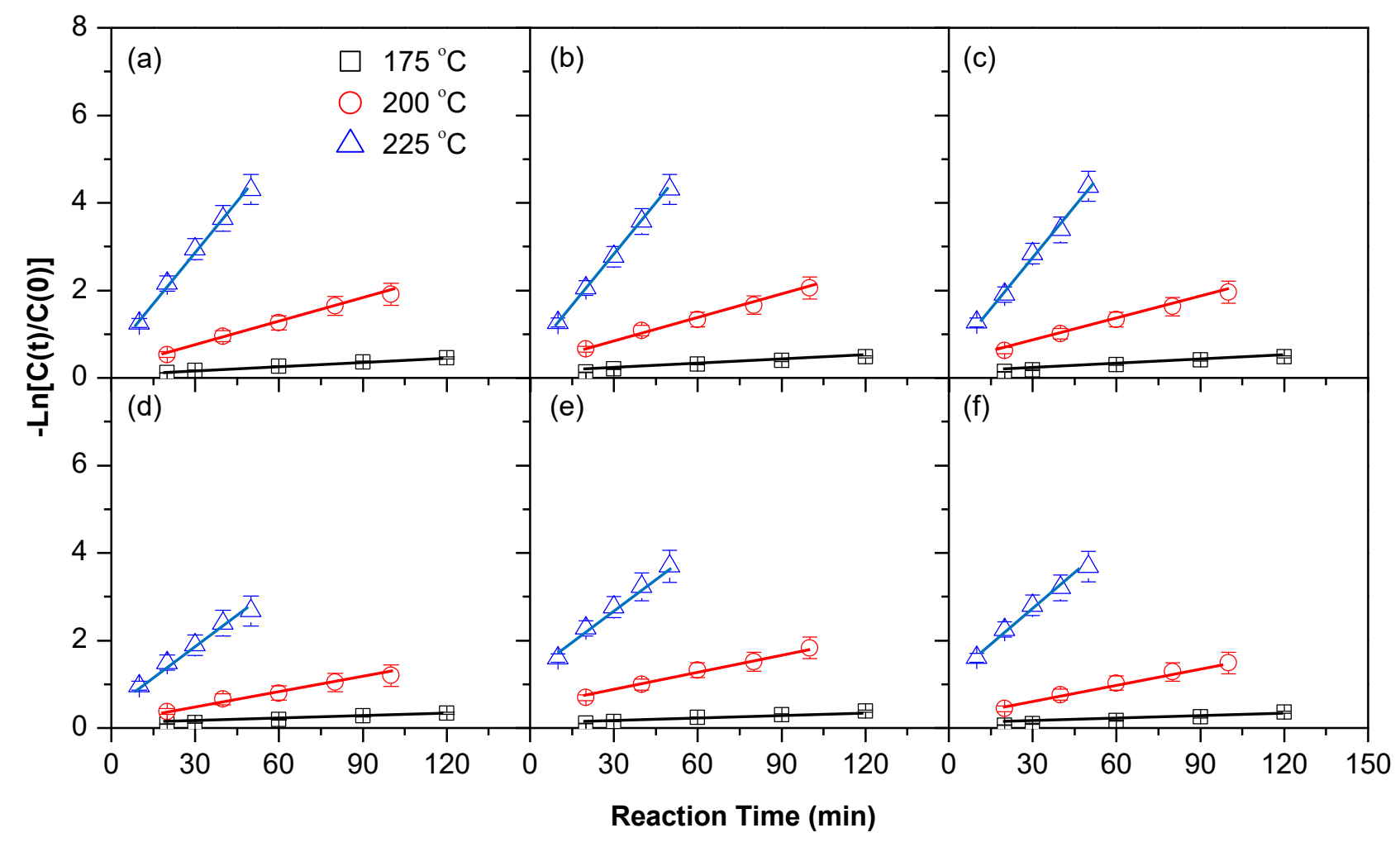

Figure S1. Correlations between $-\ln [\mathrm{C}(t) / \mathrm{C}(0)]$ and reaction time $t$ for glucose decomposition in various solvent/water mixtures. (a) water; (b) methanol/water; (c) ethanol/water; (d) GVL/water; (e) acetone/water; (f) 1,4-dioxane/water. $\mathrm{C}(0)$ and $\mathrm{C}(\mathrm{t})$ represent the primary concentration and the concentration of glucose after a reaction time $t$ at various solvent systems and temperatures. 


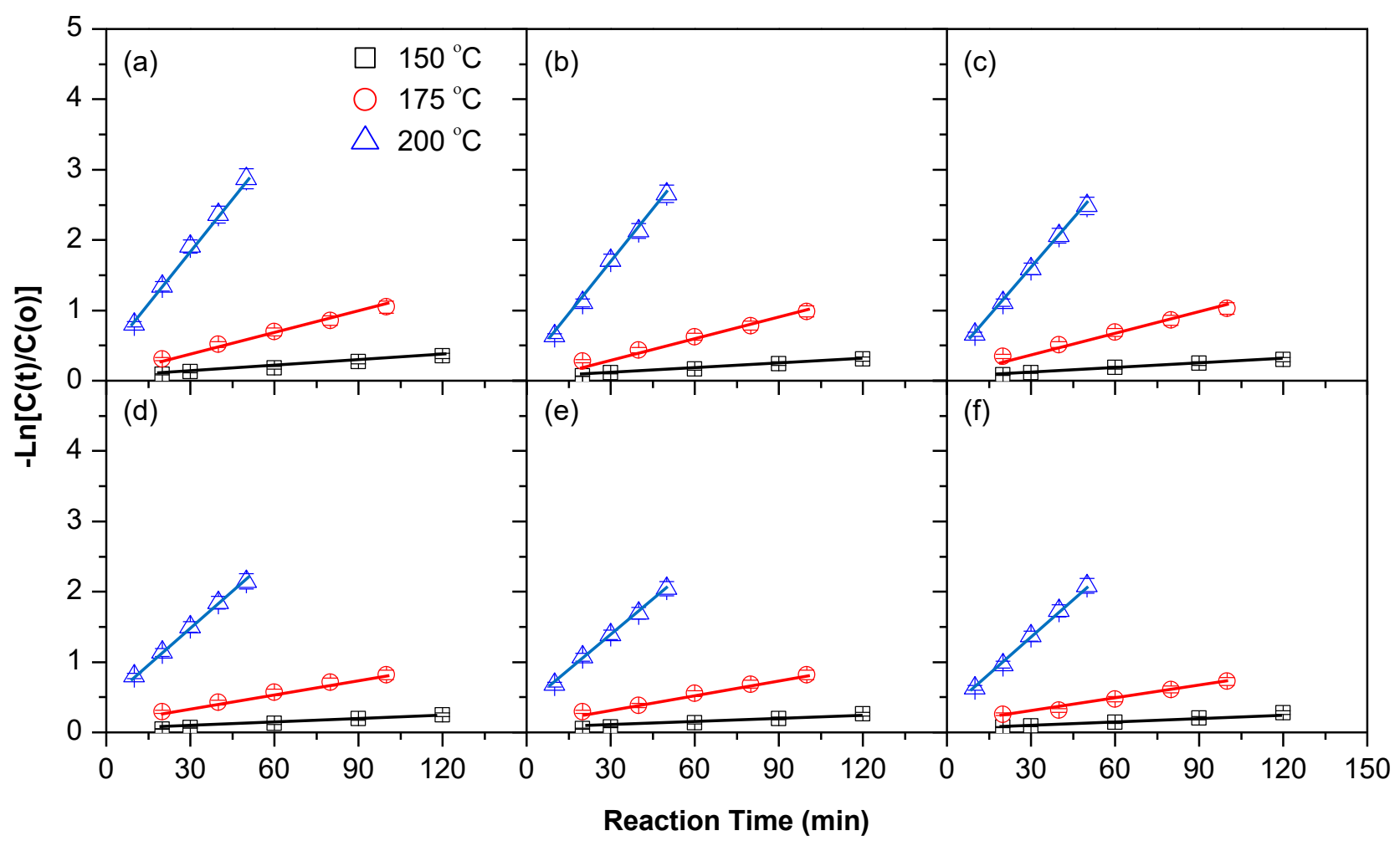

Figure S2. Correlations between $-\ln [\mathrm{C}(t) / \mathrm{C}(0)]$ and reaction time $t$ fructose decomposition in various solvent/water mixtures. (a) water; (b) methanol/water; (c) ethanol/water; (d) GVL/water; (e) acetone/water; (f) 1,4-dioxane/water. $\mathrm{C}(0)$ and $\mathrm{C}(\mathrm{t})$ represent the primary concentration and the concentration of glucose after a reaction time $\mathrm{t}$ at various solvent systems and temperatures. 

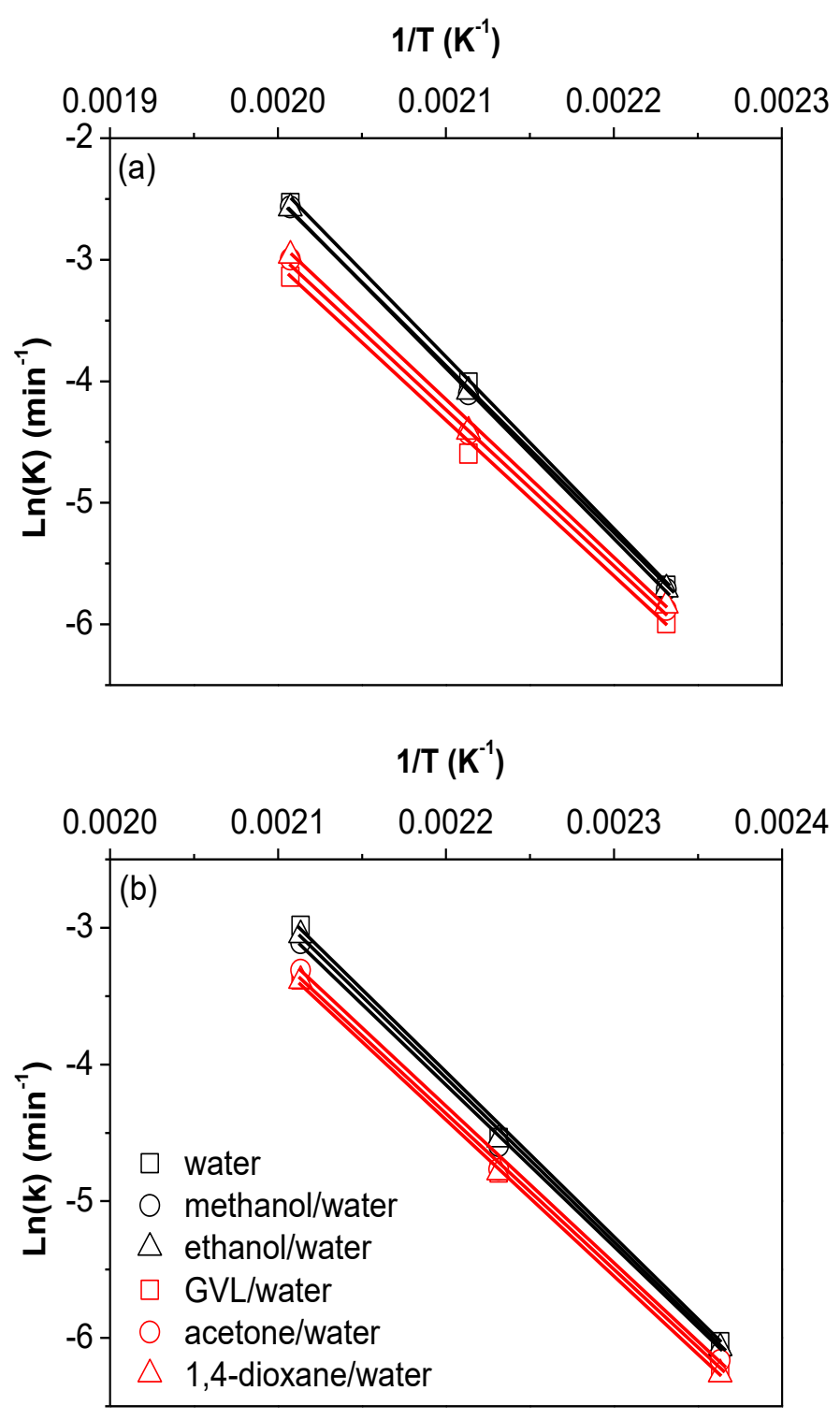

Figure S3. Arrhenius plots of glucose (a) and fructose (b) decomposition in various solvent/water mixtures. 